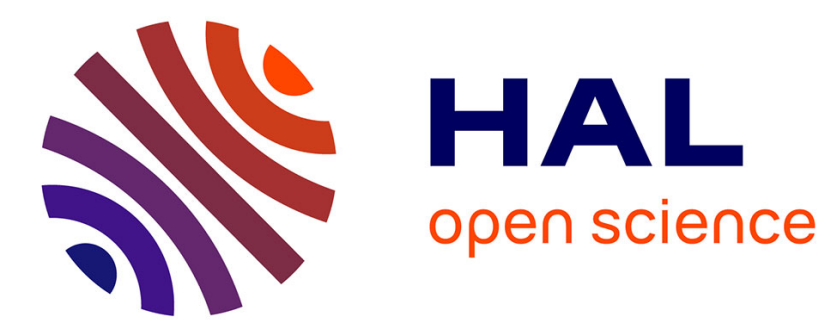

\title{
High energy density deposition inside the bulk of dielectrics via resonance absorption
}

Mostafa Hassan, Kazem Ardaneh, Rémi Meyer, Chen Xie, Cyril Billet, Luca Furfaro, Luc Froehly, Remo Giust, François Courvoisier

\section{- To cite this version:}

Mostafa Hassan, Kazem Ardaneh, Rémi Meyer, Chen Xie, Cyril Billet, et al.. High energy density deposition inside the bulk of dielectrics via resonance absorption. Conference on Lasers and ElectroOptics/Europe and the European Quantum Electronics Conference, Jun 2021, Munich, Germany. hal-03360060

\section{HAL Id: hal-03360060 https://hal.science/hal-03360060}

Submitted on 30 Sep 2021

HAL is a multi-disciplinary open access archive for the deposit and dissemination of scientific research documents, whether they are published or not. The documents may come from teaching and research institutions in France or abroad, or from public or private research centers.
L'archive ouverte pluridisciplinaire HAL, est destinée au dépôt et à la diffusion de documents scientifiques de niveau recherche, publiés ou non, émanant des établissements d'enseignement et de recherche français ou étrangers, des laboratoires publics ou privés. 


\title{
High energy density deposition inside the bulk of dielectrics via resonance absorption
}

\author{
Mostafa Hassan, Kazem Ardaneh, Remi Meyer, Chen Xie, Cyril Billet, Luca Furfaro, \\ Luc Froehly, Remo Giust, Francois Courvoisier \\ FEMTO-ST Institute, Univ. Bourgogne Franche-Comté, UMR CNRS 6174, \\ 15B avenue des Montboucons, 25030 Besançon, France
}

Ultrafast laser processing of nanochannels and nanovoids in the bulk of dielectrics such as fused silica, glass or sapphire is highly desirable for a number of applications such as stealth dicing, nano-fluidics or nano-photonics. It was demonstrated more than 10 years ago that high angle femtosecond Bessel beams can generate high aspect ratio with only a single laser pulse. However the exact mechanism of energy deposition was still lacking. Indeed, most numerical models were predicting defocussing of the pulse on the plasma, and very weak energy density deposition which was incompatible with the experimental result using an imaging technique developed in [1].

Here, we experimentally image the propagation of $100 \mathrm{fs}$ Bessel pulses in fused silica and sapphire. High absorption and absence of defocussing are demonstrated, as it is shown in Fig. 1(a).

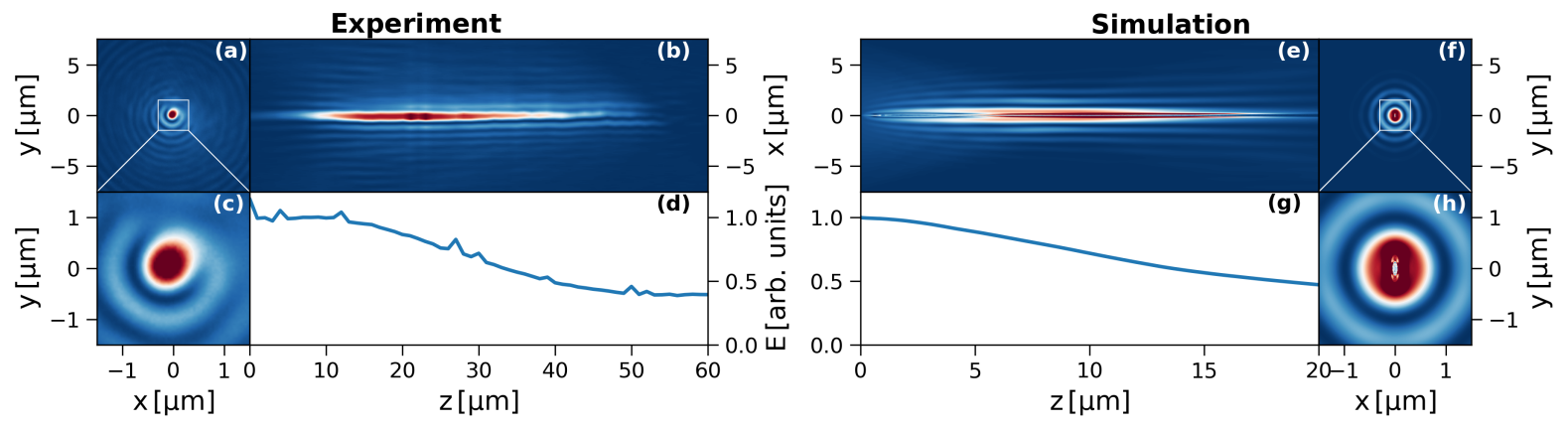

Figure 1: Comparison of near field fluence of a femtosecond Bessel pulse propagating in fused silica in experiments and simulations. Simulations are for a nanoplasma with critical diameter $125 \mathrm{~nm}$. (a,c) show experimental crosssection of the beam in the middle of the nanoplasma column $(z=30 \mu \mathrm{m})$. (d) shows the energy of the pulse as a function of propagation distance. The corresponding data are shown for numerical simulations (e-h).

We analyze the laser-plasma interaction using Particle-In-Cell (PIC) numerical simulations in 3D of a Bessel pulse impinging on a preformed cylindrical nanoplasma, using EPOCH code [2]. We demonstrate an excellent agreement with all our experimental diagnostics for fluence distributions, absorption.

Our results reveal that the nanoplasmas formed by the single Bessel pulse are overcritical, and in their diameter is well below the central spot size. It is typically on the order of $300 \mathrm{~nm}$. Our simulations also reveal the mechanism at play for energy deposition. The main mechanism is resonance absorption, which is collisionless. We investigate the role of surface waves generated in the vicinity of the critical surface in the heating and electron acceleration.

We have therefore demonstrated the generation, for the first time to our knowledge of overcritical plasmas inside the bulk of transparent dielectrics. Resonance absorption explains the extremely high energy density deposited by the laser pulse in single shot. We anticipate that our results will find applications for developing new strategies of laser materials processing and the study of Warm Dense Matter that is generated in the wake of the laser pulse.

This research has received funding from H2020 European Research Council (ERC) under grant agreement 682032-PULSAR. This work was granted access to HPC resources PRACE (Project PULSARPIC PRA19_4980), TGCC (Project A0070511001), and Mésocentre de Calcul de Franche-Comté.

\section{References}

[1] Chen Xie, Vytautas Jukna, Carles Milián, et al, "Tubular filamentation for laser material processing” Sci. Rep 5, 8914 (2015).

[2] T. D. Arber, K. Bennett, C. S. Brady, et al "Contemporary particle-in-cell approach to laser-plasma modelling," Plasma Phys. Control. Fusion 57, 113001 (2015). 